\title{
A Double-layer power allocation strategy to alleviate solar energy congestion in the distribution grid
}

\author{
Baibing Liu ${ }^{1}$, Xingzhen Bai ${ }^{1, a}$, Zhengzhong Gao ${ }^{1}$, Qiao Sun ${ }^{1}$ and Kui $\mathrm{Liu}^{2}$ \\ ${ }^{1}$ Shandong University of Science and Technology, Qingdao Shandong Province, China \\ ${ }_{2}^{2}$ State Grid Shandong Electric Power Maintenance Company, Jinan Shandong, China
}

\begin{abstract}
Many communities have their own renewable energy generators to reduce longdistance power transmission losses and to decrease greenhouse gas emissions. However, in high power demand regions, power transmission congestion is often occurred when abundant renewable energy is generated and injected into the grid, which affects the security of transmission lines and power grids. In this paper, the congestion was caused by redundance power produced by community renewable energy generators. Double-layer power allocation strategy was presented to optimize the issue. In scheduling layer, linear optimization was used to allocate power flow, and fairness was also considered. In community layer, inverters were launched or stopped in turn by operation time to minimize the number of working units and to reduce costs. 6 communities with different power production were chosen for the simulation to justify the strategy. The results show the Double-layer strategy can alleviate congestion and increase the average utilization rate of inverters.
\end{abstract}

Keywords: power congestion; local distribution grid; double-layer congestion allocation strategy; optimization.

\section{Introduction}

In the environment of electricity markets, the transmission network is now opened to public. Meanwhile, because of its clean, short construction period and investment flexibility, photovoltaic (PV) generation is popularized to more and more communities. Users can not only use their solar power, but also are able to sell the redundance power to the grid. In some regions, the permeability of distributed grid is already very high. However, because PV is easily affected by weather and illumination intensity. The intermittent redundance power from renewable energy sources can also overload the power grid, when consumption is low and transmission line doesn't have enough capability. Power transmission congestion will be more often than traditional condition.

Power transmission congestion has been one of the major issues in the power grid, especially in distribution network. Power transmission congestion refers that transmission system cannot fully meet the desired of transmission plan due to various limitations of the network.it often occurred when transmission lines' power flow or voltage overload the allowable limits [1].Traditionally, utilities tackle the congestion problem using their own rules and bidding strategies, all of them aim to maximize their profits by using tools such as unit commitment and economic dispatch in the

\footnotetext{
${ }^{\mathrm{a}}$ Corresponding author : sdkdbxz@163.com
} 
competitive electric industry [2]. Therefore, traditional strategy is considered to be passive since most methods concentrate on rescheduling generation from the supply-side, such as, rescheduling the power of thermal electric generation. However, with more solar power generated in community, congestions more often occurred in local area or even in single transmission line where traditional method is not appropriate perfectly. Congestion management strategy will be more effective and economical, if demand-side can also be considered [3-5]. With the application of smart meters, community power information is convenience to get, which will help utilities solve the congestion in demand-side effectively [6].

The main contributions of this paper are summarized in the following: 1) Double-layer power allocation strategy is presented to alleviate the power transmission congestion.2). The congestion problem is defined and formulated as one type of linear optimization. Algorithms for power allocation and inverter selection are proposed based on fairness and efficiency in different layers.

The remainder of this paper is structured as follows: Section 2 introduces the structure of the Double-layer model and the strategies of each layer and formulates the congestion problem respectively. Section 3 analyses the simulation results of the proposed strategies. Finally, Section 4 summarizes method and draws a conclusion.

\section{System model and formulation}

\subsection{Power model}

Transmission capacity is the ability that interconnected power system reliably move energy from one place to another place through the paths of all power lines or between regions under specific conditions. Available Transfer Capability (ATC) of the transmission network is a measure of the transfer capability remaining in the physical transmission network for further commercial activity over and above already committed uses [6] . ATC is calculated as

$$
A T C=T T C-T R M-E T C
$$

where TTC (total transfer capability) is the maximum amount of power that can be transferred over the network in a reliable manner while satisfying all security constraints; transmission reliability margin (TRM) is the amount of transmission transfer capability necessary to ensure the network is secure under a reasonable range of uncertainties in system conditions, and existing transmission commitments (ETC) include retail customer service and capacity benefit margin [6].ATC depends more on the values of other parameters in networks. Therefore, ATC can be considered as a dynamic parameter to measure the conditions of network.

When mounts of renewable energy injects into the transmission line and the ATC is insufficient, power transmission congestion occurred.

\subsection{Double-layer power allocation strategy in communities}

As shown in Figure1, Double-layer model is composed by scheduling layer and community layer. All the layers are communicated with internet. The information can be transferred from the utility control center to community control center to control the inverters. Community control center can also manage the inverters independently. PV arrays are laid in community public areas. Solar power is injected into the transmission line though inverters. Produces power meets the requirements of the community first, before flowing into the grid. Community users can also get the power from transmission line. The difference value between upload and download is the redundance power. When redundance power is much more than the ATC of the transmission line, the congestion occurred. Therefore, transmission congestion problem can be transformed into a power optimization problem with limited capacity. The descriptions of two layers are as follows. 


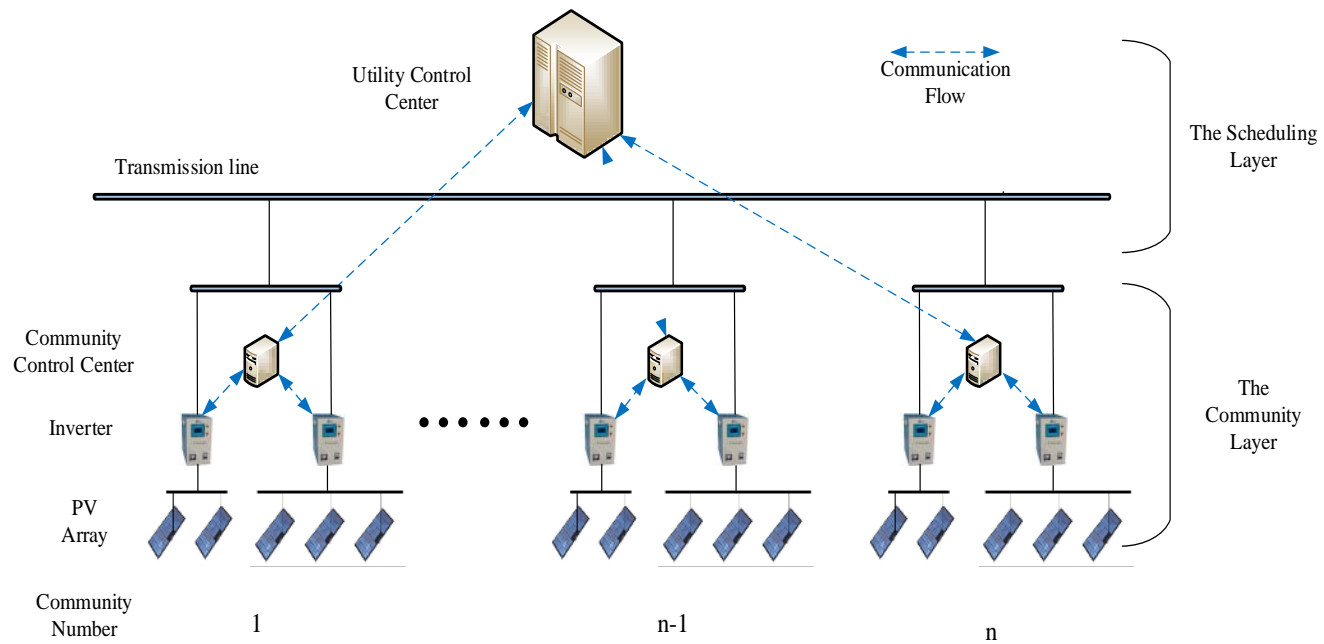

Figure 1. Double-layer model.

Symbols with definitions used for the formulation in section 2 are as follows in table 1:

Table 1. Symbols with Definitions Used for the Formulation

\begin{tabular}{|c|c|c|c|}
\hline Symbols & Definition & Symbols & Definition \\
\hline$S$ & Sum of energy utilization rate & $P_{A T C}$ & Power of Available Transfer Capability \\
\hline$P_{D i}$ & Demand power of community $i$ & $k$ & Fairness coefficient \\
\hline$P_{G i}$ & Generated power of community $i$ & $n$ & Total number of community \\
\hline$P_{u p}$ & Upload power of community $i$ & $m$ & Total number of inverter in one community \\
\hline$P_{u p r e f}$ & Predicted upload power & $P_{j}^{\text {ref }}$ & Predicted upload power of inverter $j$ \\
\hline$P_{j}^{\text {max }}$ & Rated power of inverter $j$ & $x_{j}$ & Inverter ON/OFF status \\
\hline$\eta_{i}$ & Energy utilization rate & $P_{S i}$ & Surplus power of community $i$ \\
\hline
\end{tabular}

\subsubsection{The scheduling layer}

In scheduling layer, total generation and demand power data of all community will be collected to the utility. When congestion occurred, utility will schedule the power plan for every community.

Different from PV power station, Household PV power generation in most country adopt strategy "Self-Consume the generated, connect the redundance to grid". In other words, the generated should meet local users first, redundance power will connect to the grid. Energy utilization rate becomes a target when ATC is not enough to let all redundance connect to grid.

$$
\begin{gathered}
\max s=\sum_{i=1}^{n} \eta_{i} \quad \text { s.t. } \sum_{i=1}^{n} P_{\text {upi }} \leq P_{\text {upref }} \\
\eta_{i}=\left\{\begin{array}{lc}
1 & P_{D i} \geq P_{G i} \\
\frac{P_{D i}}{P_{G i}} \leq \eta_{i} \leq 1 & P_{D i}<P_{G i}
\end{array}\right. \\
P_{u p i}=P_{D i}+P_{S i}
\end{gathered}
$$




$$
P_{\text {uoref }}=P_{\text {ATC }}+\sum_{i=1}^{n} P_{D i}
$$

If the power demand of a community is greater than or equal to the generated, the energy utilization rate in this community equals 1 and the capacity of the generated will not be changed. On the contrary, the energy utilization rate in this community will less than 1 , power generation of this community will be rescheduled. However, communities with low power generation will more easy to get high energy utilization rate, which is unfair for others. In order to ensure the fairness. Average energy utilization rate is considered as a standard. Fairness coefficient $\mathrm{k}$ is defined to describe the acceptable level from the standard.

$$
\text { s.t. } \quad \eta_{i} \geq k \times \frac{P_{\text {upref }}}{\sum_{i=1}^{n} P_{G i}} \quad 0<k \leq 1
$$

\subsubsection{The community layer}

In community Layer, power will be effectively allocated to inverters located in every community after receiving power data from scheduling Layer. Data form upper layer often lower than the maximum predicted generation value. Therefore, inverters will adjust output power to decrease redundance power. The maximum power generation proportion strategy is commonly used in the past.

$$
P_{j}^{r e f}=P_{j}^{\max } \times \frac{P_{u p i}}{\sum_{j=1}^{m} P_{j}^{\max }}
$$

However, when seriously congestion happens, values of each inverter calculated in maximum power generation proportion strategy are very low, so as to the efficiency. Meanwhile, it will reduce the life of the inverter, if inverters are always in uninterrupted running condition, which may increase maintenance costs. Therefore, new strategy is proposed to launch or stop inverters in turn. This also can be described as optimization problem, aiming to minimize the number of working inverters and reduce the average operation time.

$$
\begin{gathered}
\min N=\sum_{j=1}^{m} x_{i} \quad \text { s.t. } \quad P_{j}^{\min } \leq P_{j}^{r e f} \leq P_{j}^{\max } \\
\sum_{j=1}^{n} P_{j}^{r e f} \leq P_{u p}
\end{gathered}
$$

The new strategy should submit to the following principles:

(1)Inverters having long operation time will be stop first.

(2) To ensure inverters have maximum efficiency

The specific process is as follows:

First, we will sort the inverters in descending order of average operation time, and assume all inverters are launching $\left(x_{j}=1\right)$. The following recursive computations are performed until $\mathrm{m}$ turns negative (assuming $j=\mathrm{r}$ ).

Then let $x_{1}$ to $x_{r-1}$ equal to 0 , others still equal to 1 . However, the rth inverter may not operate in fully loaded. Calculate the power value of the rth inverter:

$$
w=P_{u p}-\sum_{j=r+1}^{m} P_{j}
$$


Compare the power value from 1st to (r-1) th, selecting the value closest to the power value of the rth inverter, and let it operate.

At last, the maximum power generation proportion strategy is used to allocate the power in operational inverters.

\section{Simulation results and analysis}

We simulate 6 communities with different scale in power production, 2 small communities, 2 medium communities and 2 large communities(Table2). Fairness coefficient $\mathrm{k}=0.8$, simulation will be made when ATC is severe shortage $(\mathrm{ATC}=400 \mathrm{~kW})$ and slight shortage $(\mathrm{ATC}=2200 \mathrm{~kW})$. As we see in the table 2, the value of demand power in NO.1 community is more than that of maximum predicted power. When congestion occurred, it will remain condition. Others will change their outputs according the first layer algorithm. When ATC $=400 \mathrm{~kW}$, according to the algorithm, power production value will be reallocated (Table 2, line 4). Each of them are no more than maximum predicted power value (Table 2, line 1). The sum of values is less than $6400 \mathrm{~kW}$. We can draw a conclusion in a similar way, when ATC $=2200 \mathrm{~kW}$.

Table 2. Power of 6 Communities in different ATC

\begin{tabular}{|c|c|c|c|c|c|c|c|}
\hline Community Number & 1 & 2 & 3 & 4 & 5 & 6 & Total \\
\hline $\begin{array}{c}\text { Maximum Predicted } \\
\text { Power Value(kW) }\end{array}$ & 800 & 800 & 1500 & 1500 & 2000 & 2000 & 8600 \\
\hline $\begin{array}{c}\text { Demand Power Value } \\
(\mathrm{kW})\end{array}$ & 850 & 650 & 1000 & 950 & 1000 & 1550 & 6000 \\
\hline $\begin{array}{c}\text { Actual Power Value } \\
(\mathrm{kW})(\text { ATC=400) }\end{array}$ & 800 & 800 & 1050.3 & 1009.05 & 1190.6 & 1550 & 6400 \\
\hline $\begin{array}{c}\text { Energy Utilization } \\
\text { Rate (ATC=400) }\end{array}$ & 1 & 1 & 0.7002 & 0.6727 & 0.5953 & 0.7750 & 4.732 \\
\hline $\begin{array}{c}\text { Actual Power Value } \\
\text { (kW)(ATC=2200) }\end{array}$ & 800 & 800 & 1500 & 1500 & 1791.2 & 1808.8 & 8200 \\
\hline $\begin{array}{c}\text { Energy Utilization } \\
\text { Rate(ATC=2200) }\end{array}$ & 1 & 1 & 1 & 1 & 0.8956 & 0.9044 & 5.8 \\
\hline
\end{tabular}

We select NO.5 community to simulate the second layer strategy (Table3,Table4), when ATC is severe shortage $($ ATC $=400 \mathrm{~kW})$ and slight shortage $($ ATC $=2200 \mathrm{~kW})$. Assuming that there are 8 inverters in this community. The predicted power values are different since the illumination .The smaller ID number is, the longer time the inverter operates.

As we can see from the tables, when ATC $=400 \mathrm{~kW}$ and ATC $=2200 \mathrm{~kW}$, amount of power can't be injected in grid.In order to keep inverters working in an efficient way and cut off the unnecessary cost,some of the inverter will be stopped. Meanwhile the power production value of the remainings will be reallovated through the our new strategy((8)-(10)). Maximum power generation proportion strategy is used for comparison.

Compared with two strategies, all inverter were not operated in full-load when maximum power generation proportion strategy was used. Therefore, the average utilization rate of the inverter was low. On the contrary, new strategy has high average utilization rate, no matter which conditions occurred. The number of inverter is reduced significantly, and the efficiency of inverters is guaranteed as well. 
Table 3. Situations of Inverters in NO.5 Community (ATC $=400 \mathrm{~kW})$

\begin{tabular}{|c|c|c|c|}
\hline \multirow[t]{2}{*}{ Inverter ID } & \multirow[t]{2}{*}{$\begin{array}{c}\text { Predicted } \\
\text { Power Value } \\
(\mathrm{kW})\end{array}$} & New Strategy & $\begin{array}{c}\text { Maximum Power } \\
\text { Generation Proportion } \\
\text { Strategy }\end{array}$ \\
\hline & & Power Value (kW) & Power Value (kW) \\
\hline 1 & 100 & 0 & 59.53 \\
\hline 2 & 200 & 198.42 & 119.06 \\
\hline 3 & 300 & 0 & 178.59 \\
\hline 4 & 400 & 0 & 238.12 \\
\hline 5 & 100 & 99.21 & 59.53 \\
\hline 6 & 200 & 198.42 & 119.06 \\
\hline 7 & 300 & 297.65 & 178.59 \\
\hline 8 & 400 & 396.86 & 238.12 \\
\hline Total & 2000 & 1190.6 & 1190.6 \\
\hline Average Utilization Rate & & 0.9921 & 0.5953 \\
\hline
\end{tabular}

Table 4. Situations of Inverters in NO.5 Community (ATC=2200kW)

\begin{tabular}{|c|c|c|c|}
\hline \multirow[t]{2}{*}{ Inverter ID } & \multirow{2}{*}{$\begin{array}{l}\text { Predicted } \\
\text { Power Value } \\
(\mathrm{kW})\end{array}$} & New Strategy & $\begin{array}{c}\text { Maximum Power } \\
\text { Generation Proportion } \\
\text { Strategy }\end{array}$ \\
\hline & & Power Value $(\mathrm{kW})$ & Power Value (kW) \\
\hline 1 & 100 & 99.45 & 89.51 \\
\hline 2 & 200 & 0 & 179.02 \\
\hline 3 & 300 & 298.36 & 268.53 \\
\hline 4 & 400 & 397.82 & 358.04 \\
\hline 5 & 100 & 99.45 & 89.51 \\
\hline 6 & 200 & 198.91 & 179.02 \\
\hline 7 & 300 & 298.36 & 268.53 \\
\hline 8 & 400 & 397.82 & 358.04 \\
\hline Total & 2000 & 1790.2 & 1790.2 \\
\hline Average Utilization Rate & & 0.9946 & 0.8951 \\
\hline
\end{tabular}

\section{Conclusion}

In this paper, we have investigated congestion in the electric power system. Power transmission congestion can occur due to variability of demands and intermittency of renewable energy when network is limited. We formulate the congestion issue in the distribution grid as one type of optimization problem, and alleviate it with Double-layer power allocation strategy. The simulation results show that the congestion can be solved effectively and efficiently.

For the future work, we will investigate the data interrupt due to information transmission in double-layer modle. Furthermore, more fairness in selection should also be determined. Moreover, combining other distributed generation such as wind and storage battery with the PV solar system will also be considered in our future research.

\section{References}

1. J Kabouris, CD Vournas, S Efstathiou, GA Manos, DRPT , 278-283(2000) ;

2. RC Dorf, The electrical engineering handbook (CRC Press,2006) ;

3. MH Moradi, S Dehghan, A Mirzaei,Int.Rev.Elec. Eng.6, 1447-1454 (2011) ;

4. J Liu, MMA Salama, RR Mansour,IEEE Trans.Power Del. 20, 1998-2005( 2005) ;

5. B Liu, J Kang, N Jiang, Y Jing, Energy Power Eng., 3, 17-23(2011) ;

6. CH Lo, N Ansari,IEEE Trans.Parallel Distrib.Syst. 23, 1607-1620(2012). 